\title{
Status of the Thirty Meter Telescope site selection program
}

\section{Matthias Schöck, Sebastian Els, Reed Riddle, Warren Skidmore, Tony Travouillon, et al.}

Matthias Schöck, Sebastian Els, Reed Riddle, Warren Skidmore, Tony Travouillon, Robert Blum, Edison Bustos, Paul Gillett, Brooke Gregory, Jerry Nelson, Angel Otarola, Juan Seguel, Joselino Vasquez, Konstantinos Vogiatzis, David Walker, Lianqi Wang, "Status of the Thirty Meter Telescope site selection program," Proc. SPIE 7012, Ground-based and Airborne Telescopes II, 70121X (10 July 2008); doi: 10.1117/12.789704

SPIE Event: SPIE Astronomical Telescopes + Instrumentation, 2008, Marseille, France 


\title{
Status of the Thirty Meter Telescope site selection program
}

\author{
Matthias Schöck ${ }^{a}$, Sebastian Els $^{b}$, Reed Riddle ${ }^{a}$, Warren Skidmore ${ }^{a}$, Tony Travouillon ${ }^{a}$, \\ Robert Blum ${ }^{c}$, Edison Bustos ${ }^{b}$, Paul Gillett ${ }^{a}$, Brooke Gregory $^{b}$, Jerry Nelson ${ }^{d}$, Angel \\ Otárola $^{a}$, Juan Seguel ${ }^{b}$, Joselino Vasquez ${ }^{b}$, Konstantinos Vogiatzis ${ }^{a}$, David Walker ${ }^{b}$, Lianqi \\ Wang $^{a}$ \\ ${ }^{a}$ TMT Observatory Corporation, Pasadena, CA, USA; \\ ${ }^{b}$ Cerro Tololo Inter-American Observatory, La Serena, Chile; \\ ${ }^{c}$ National Optical Astronomy Observatory, Tucson, AZ, USA; \\ ${ }^{d}$ University of California, Santa Cruz, CA, USA
}

\begin{abstract}
The Thirty Meter Telescope (TMT) project has been collecting data on five candidate sites since 2003. This paper describes the site testing portion of the TMT site selection program and the process and standards employed by it. This includes descriptions of the candidate sites, the process by which they were identified, the site characterization instrument suite and its calibration and the available results, which will be published shortly.
\end{abstract}

Keywords: Site testing, site selection, ELTs

\section{INTRODUCTION}

This paper provides a summary of the Thirty Meter Telescope (TMT) site testing program that was conducted to support a site selection. The principles underlying this program and the selection of candidate sites were already described in Ref. 1. Some of them are repeated here in abbreviated or updated form in order to provide the reader with a complete and consistent picture of the process. In addition, more information about the instruments and instrument calibrations is given and the available results are described. The results from the site testing period will be published shortly.

TMT needs to be built on the best available site in order to obtain the maximum return from its science potential. Careful site testing has therefore been extremely important to TMT from the very beginning of the project. The site testing process started in $2001 / 2002$, in a collaboration between the AURA New Initiatives Office (NIO) and the California Extremely Large Telescope (CELT), with the selection of five candidate sites to be studied in detail. The sites were studied via the operation of remote site monitoring stations starting in 2003.

The TMT site needs to be suited for producing astronomical data of superb quality and for building and operating an observatory of the size and complexity of TMT. Strict technical requirements as they apply to other parts of the project do not exist for the TMT site, as there are many combinations of site parameters entering the TMT site decision which may define an excellent site for TMT. Instead, the site selection process involves measuring and predicting both the technical and programmatic properties of the sites and balancing them so as to determine the site that best meets the TMT needs. It is not a priori obvious how to combine all the parameters to arrive at the final site decision. A series of steps have therefore been taken by the TMT Project to develop a method of dealing with the complexity of the TMT site selection process. These include the development of a site ranking metric which provides a method for an objective comparison of the technical properties of the candidate sites and their science producing implications, the issuing of several comprehensive intermediate reports, quarterly results update reports as well as quarterly internal and approximately annual external reviews. These steps have proven to be invaluable for the both the site testing team and the TMT project and served their intended purpose of providing information to the parties involved in the site decision and of fine-tuning our data analysis and site comparison methodology.

Further author information: Send correspondence to M.S., e-mail: mschoeck@tmt.org

Ground-based and Airborne Telescopes II, edited by Larry M. Stepp, Roberto Gilmozzi, Proc. of SPIE Vol. 7012, 70121X, (2008) · 0277-786X/08/\$18 · doi: 10.1117/12.789704 


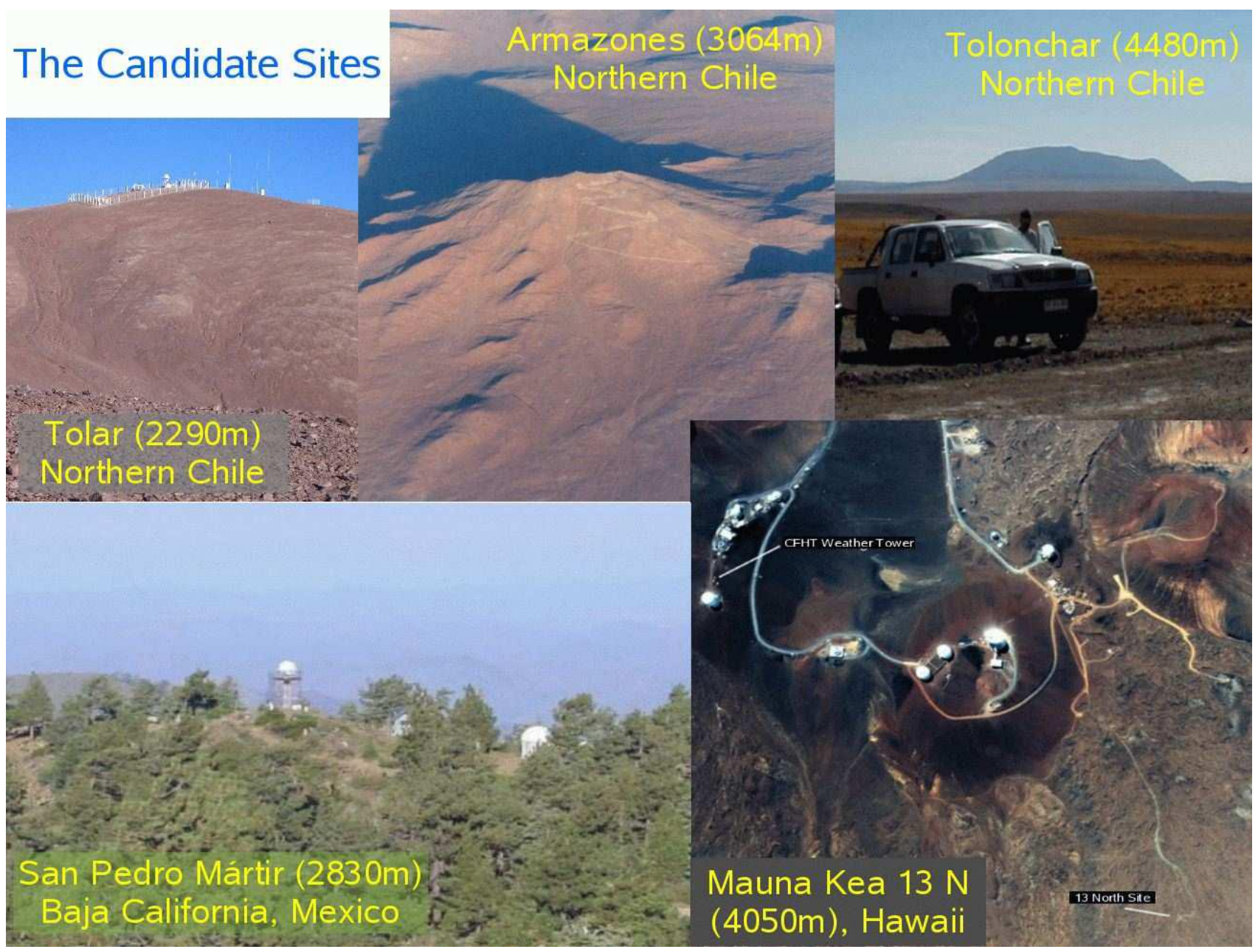

Figure 1. Views of the five TMT candidate sites.

In addition to being scientifically qualified, the TMT site must also meet observatory technical and programmatic needs. Obtaining legal access to the site when required in the construction schedule is a primary factor, but other considerations such as labor, logistics, geological conditions and the permitting process are also considered in the site selection.

\section{CANDIDATE SITES}

TMT selected five sites as candidate observatory sites and began on-site testing in 2003 (see Table 2 in Section 3 for details of the instrument deployment schedule). The site testing process started by considering as complete a list as possible of potentially interesting sites everywhere in the world. It was narrowed down using existing knowledge from previous site testing studies and from established observatory sites. The final list of candidate sites was selected based on satellite studies of cloud cover and precipitable water vapor done by Dr. D.A. Erasmus and his group. The names of the five candidate sites and their coordinates and location are listed in Table 1. Views of each of the candidate sites are shown in Fig. 1. Brief general descriptions of the sites and their locations are given in the following, see Ref. 1 for more details.

\section{Cerro Tolar:}

A low elevation site $(2290 \mathrm{~m})$ in northern Chile, Cerro Tolar is in the Atacama desert and has an extremely arid climate. Tolar is located at a distance of only $8 \mathrm{~km}$ from the coast, at $16 \mathrm{~km}$ from the closest paved road and $18 \mathrm{~km}$ north-north-east of Tocopilla, a town of 25,000 inhabitants. 
Table 1. List of TMT candidate sites selected for on-site testing.

\begin{tabular}{|l|c|c|c|c|}
\hline Site Name & Elevation & $\begin{array}{c}\text { Latitude } \\
\text { [deg N] }\end{array}$ & $\begin{array}{c}\text { Longitude } \\
{[\operatorname{deg~W}]}\end{array}$ & Characteristics \\
\hline \hline Cerro Tolar & $2290 \mathrm{~m}$ & -21.9639 & 70.0997 & Northern Chile, coastal site \\
Cerro Armazones & $3064 \mathrm{~m}$ & -24.5800 & 70.1833 & Northern Chile, coastal site \\
Cerro Tolonchar & $4480 \mathrm{~m}$ & -23.9333 & 67.9750 & Northern Chile, inland site \\
San Pedro Mártir & $2830 \mathrm{~m}$ & 31.0456 & 115.4691 & Baja California, Mexico; 60 km from ocean \\
Mauna Kea 13N & $4050 \mathrm{~m}$ & 19.8330 & 155.4810 & Big Island, Hawai'i; island site \\
\hline
\end{tabular}

\section{Cerro Armazones:}

Cerro Armazones, a medium elevation site $(3064 \mathrm{~m})$ in northern Chile, is also located in the Atacama desert and close to the coast $(36 \mathrm{~km})$, with a climate very similar to that of Tolar. It is $22 \mathrm{~km}$ from ESO's Very Large Telescope (VLT) on Cerro Paranal and $110 \mathrm{~km}$ south of Antofagasta, the closest city.

\section{Cerro Tolonchar:}

Cerro Tolonchar is the eastern-most of the Chilean sites, south of the Salar de Atacama. Because of its eastern location and higher altitude, it experiences more precipitation and clouds than Tolar and Armazones, especially during the South American summer monsoon, ${ }^{2}$ also known as the "Bolivian Winter", from approximately mid December to mid February. Tolonchar is also the highest $(4480 \mathrm{~m})$ and most remote of all TMT candidate sites at $190 \mathrm{~km}$ from Calama, the closest large city with a commercial airport.

\section{San Pedro Mártir:}

San Pedro Mártir (SPM) is located in northern Baja California, Mexico, inside a national park and is the site of the Observatorio Astronómico Nacional de San Pedro Mártir. It is a medium-elevation site $(2830 \mathrm{~m}), \sim 65 \mathrm{~km}$ from the Pacific coast in the west and $55 \mathrm{~km}$ from the Sea of Cortez (Gulf of California) to the east. The closest large city is Ensenada at $140 \mathrm{~km}$ line-of-sight distance, with the Tijuana / San Diego area at $220-250 \mathrm{~km}$.

\section{Mauna Kea 13N:}

The TMT candidate site on Mauna Kea on the Big Island of Hawaii is a location referred to as "13 North" $(13 \mathrm{~N})$ on the northern shield, approximately $150 \mathrm{~m}$ below the summit. It is adjacent to the Submillimeter Array (SMA) extension area. With $\sim 4050 \mathrm{~m}$ elevation, $13 \mathrm{~N}$ is the second highest of the TMT candidate sites.

\section{THE TMT SITE TESTING INSTRUMENT SUITE}

The TMT site decision will be based on both technical and programmatic aspects. Technical site properties are assessed predominantly through data acquired in a multi-year study of the site conditions using identical equipment. To acquire these data, the TMT site testing team has been operating remote site monitoring stations at each of the candidate sites. Considerable effort has gone into calibrating all equipment through side-by-side comparisons of identical instruments and, when possible, by comparison with other instruments. This section contains a summary of the instrument suite, the deployment dates to the sites and the measurement uncertainties we have determined for the individual parameters.

\subsection{Instrument Overview}

The following instruments have been deployed at the candidate sites (see also Fig. 2):

\section{Differential Image Motion Monitors (DIMM):}

Differential image motion monitors (DIMMs) are currently the standard for measuring the integrated atmospheric seeing. ${ }^{3}$ The TMT instruments were constructed at the Cerro Tololo Inter-American Observatory (CTIO) and are mounted on custom-made $35 \mathrm{~cm}$ telescopes manufactured by Teleskoptechnik Halfmann. At 


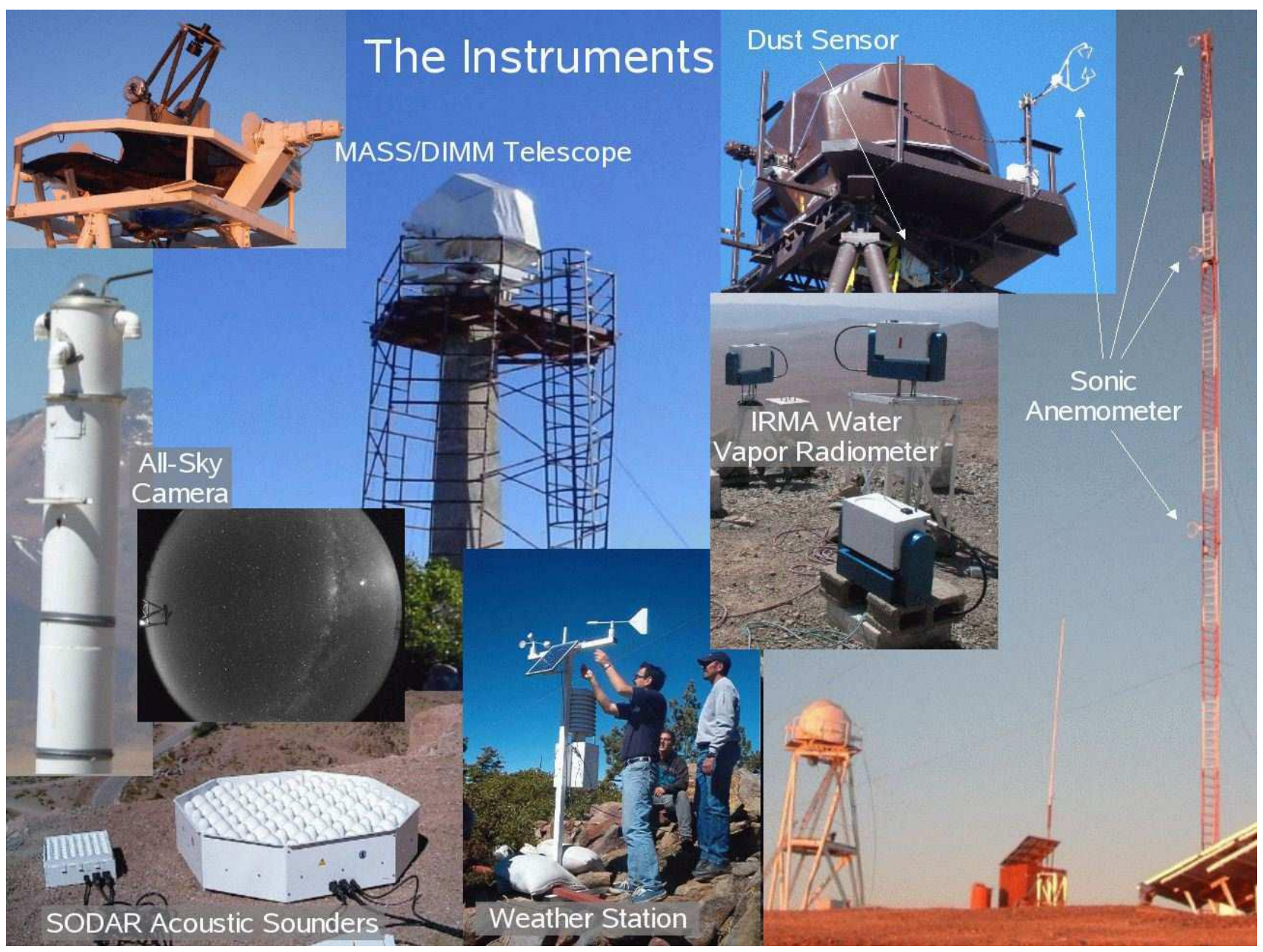

Figure 2. The TMT site testing instrument suite.

the candidate sites, the telescopes are installed on $6.5 \mathrm{~m}$ towers. We use our DIMMs to measure the seeing, its temporal variability ${ }^{4}$ and to verify isoplanatic angle, turbulence coherence time, cloud cover and atmospheric transparency results taken with other instruments.

As the seeing is one of the most important parameters entering the TMT site decision, a large effort was undertaken to determine the repeatability and accuracy of our seeing measurements in several side-by-side comparison campaigns of identical and non-identical DIMMs and through comparisons with other instruments such as MASSs and SODARs (see below). The result of the calibration effort is given in Table 3. Details are described in Ref. 5.

\section{Multi-Aperture Scintillation Sensors (MASS):}

Integrated in the same physical instrument as the DIMM is a Multi-Aperture Scintillation Sensor (MASS). The MASS/DIMM units were built in a collaboration between CTIO and the Sternberg Astronomical Institute in Moscow, Russia. A MASS produces six-layer measurements of the turbulence profile, excluding the first few hundreds of meters. ${ }^{6}$ The layers are centered around 0.5, 1, 2, 4, 8 and $16 \mathrm{~km}$ elevation. The ground layer turbulence strength can then be calculated from the difference between the DIMM and MASS seeing. In addition to turbulence profiles, we also measure the isoplanatic angle, atmospheric coherence time ${ }^{7,8}$ and temporal variability of the MASS seeing. ${ }^{4}$ Atmospheric transparency measurements are also taken and cloud cover measurement from the all-sky cameras (described below) are verified. ${ }^{8,9}$ 
Although the MASS instrument is quickly becoming one of the standard instruments for turbulence-profiling using small (tens of centimeter diameter) telescopes, neither the reproducibility nor the accuracy of the measurements were known at the beginning of the TMT site testing campaign. We therefore have undertaken a large effort to understand the calibration and uncertainties of the TMT MASS instruments. The main results are given in Table 3, details in Refs. 7 and 8.

\section{Sound Detection and Ranging (SODAR) acoustic sounders:}

SODAR (SOund Detection And Ranging) is the acoustic equivalent of RADAR. SODAR instruments have the capability of measuring both turbulence and wind velocity profiles in the atmospheric ground layer with high resolution. In order to study the lower part of the atmosphere, below the range of the MASS, we use a pair of SODARs that complement each other to sample elevations from $10-800 \mathrm{~m}$. The first SODAR is a low range, high resolution model (SFAS by Scintec). We operate it in a way that it produces a turbulence and wind velocity profile from $10-200 \mathrm{~m}$ every 30 minutes, with a resolution of $5 \mathrm{~m}$. The second model is a high power, high range SODAR (XFAS) that operates from $40-800 \mathrm{~m}$ with a vertical resolution of $20 \mathrm{~m}$. The combined range of the two SODARs fills the elevation gap between the DIMM ( $7 \mathrm{~m}$ above the ground) and the first turbulence layer sensed by the MASS. TMT operates three sets which are rotated among the sites.

SODARs are notorious for their difficult calibration which caused us to spend a significant effort on developing and verifying new calibration methods. This is described in Ref. 10. The resulting estimated uncertainties of the measurements are listed in Table 3.

\section{Automatic Weather Stations (AWS):}

Commercial automatic weather stations (AWSs) from Monitor Sensors are deployed at all sites. These measure air temperature, wind speed and direction, relative humidity, barometric pressure, solar irradiance and the occurrence of precipitation. The net radiation above the ground and the ground heat flux are also measured whenever a SODAR is running at a site. Soil temperature sensors have been used at Tolar (entire testing period), Armazones (since January 2007) and Tolonchar (since March 2007), but are not part of the standard site setup. The AWS sensors are installed between 1.5 and $2.5 \mathrm{~m}$ above the ground.

At each site, a sonic anemometer (CSAT-3 model by Campbell Scientific) is placed at the level of the MASS/DIMM telescope, $7 \mathrm{~m}$ above the ground. It measures a "sonic temperature" (proportional to temperature, but also dependent on humidity and other parameters) and wind speed and direction. The raw data for turbulence measurements are also taken and saved.

On recommendation by the TMT External Advisory Panel, we installed $30 \mathrm{~m}$ towers on Armazones (September 2006) and Tolonchar (March 2007). These are equipped with sonic anemometers and air temperature sensors at the 11, 20 and 30 (or 28) m levels. A $30 \mathrm{~m}$ tower was also set up and operated by the Large Synoptic Survey Telescope (LSST) project at San Pedro Mártir from December 2005 to May 2006. It was equipped with Metek USA-1 sonic anemometers at the 7, 12, 19 and $30 \mathrm{~m}$ tower levels. The data are available to TMT through a data-sharing agreement involving all instruments either project has deployed at San Pedro Mártir. The base of the San Pedro Mártir $30 \mathrm{~m}$ tower was approximately $6 \mathrm{~m}$ below the base of the MASS/DIMM telescope tower. This difference is $\sim 2 \mathrm{~m}$ at Tolonchar and less than $1 \mathrm{~m}$ at Armazones.

Data from the AWSs are downloaded once every two minutes, except when there is a $30 \mathrm{~m}$ tower installed at the site, in which case they are read once every minute. The stations are configured such that the delivered values are averages over the previous minute. The temperature probes on the tower are set up to produce measurements every 2 seconds. These measurements are instantaneous values. Sonic anemometer raw data are taken and saved at $60 \mathrm{~Hz}$. Currently, only averages of one-minute subsets of the sonic data are analyzed. If desired, the raw data can be used for temporal power spectra analyses at a later time. ${ }^{11}$

\section{All-sky cameras (ASCA):}

All-sky cameras (ASCAs) are deployed at all candidate sites. The TMT ASCAs are replicas of the Tololo ASCA and were built by CTIO. The ASCA deployed at San Pedro Mártir is owned by LSST. A detailed description of the cameras is given in Ref. 12. We use the ASCAs mainly to measure cloud cover and light 
pollution at the candidate sites. This is described in detail in two other papers at this conference. ${ }^{9,13}$ The usable observing time fraction of the sites is also assessed based on these measurements.

\section{Infrared Radiometers for Millimetre Astronomy (IRMA):}

Three Infrared Radiometer for Millimetre Astronomy (IRMA) units were contracted to the University of Lethbridge. An IRMA measures the sky flux around $20 \mu \mathrm{m}(\sim 16.5-21.5 \mu \mathrm{m})$ wavelength and derives a precipitable water vapor (PWV) value from this flux by use of a suitable atmospheric model. ${ }^{14}$ The devices were first delivered at the end of January 2006 and tested side-by-side during three weeks on Cerro Paranal in collaboration with the European Southern Observatory (ESO) site monitoring group. After that, additional hardware modifications and calibration method development were done. The three units were redeployed for another round of side-by-side comparisons on Armazones in January of 2007. One unit was moved to Mauna Kea 13N in February 2007 and one to Tolonchar in March 2007, while the third remained on Armazones. We have shown that different IRMA units deployed at the same site produce results that are reproducible on the $0.25-$ $0.5 \mathrm{~mm}$ level and that they are correlated with the measurements by other PWV radiometers on approximately the same level. The absolute calibration is, however, difficult and depends among other things on the exact atmospheric model used.

\section{Dust Sensors:}

The dust sensors are commercial units from Met One Instruments. They measure the particle count in five different channels, for particle sizes $0.3,0.5,1.0,2.0$ and $5.0 \mu \mathrm{m}$. Here, the given size is a lower limit, each channel counts all particles with sizes equal to or larger than the respective value. The vendor quotes an accuracy of $10 \%$ for the individual measurement. We undertook a side-by-side calibration of the sensors in the lab in Pasadena and confirmed that the results are comparable on this level. An absolute calibration was not attempted.

The TMT instrument suites are robotic and autonomous systems that do not require any operators or user interventions for standard operation. Nevertheless, they are constantly connected via the Internet, enabling full manual control and a wide variety of remote trouble-shooting. Data are available in real time via a website and are automatically loaded into a central database each morning. The robotic system is described in Ref. 15.

In addition to the on-site testing, other methods used to characterize the sites are:

\section{Computational Fluid Dynamics (CFD) Simulations:}

Many computational fluid dynamics (CFD) simulations have been performed for the TMT candidate sites. Besides simulations of the site conditions themselves, these include comparisons with radiosondes and site testing equipment on Tololo, analyses of the sensitivity of the simulation results to the input parameters for San Pedro Mártir, Mauna Kea and Tolonchar, and a study comparing changes in conditions predicted by CFD with onsite measurements. ${ }^{16}$ These studies show good qualitative agreement between measurements and simulations. Quantifying the agreement will be done during the site characterization phase (following the down-selection to two sites), when we are planning to have several site testing stations deployed at Cerro Armazones in order to monitor the turbulent flow over the site. CFD simulations are also used extensively in the analysis of other aspects of TMT, such as dome and mirror seeing and wind buffeting, as is reported elsewhere in these proceedings.

\section{Satellite Studies of Cloud Cover and PWV:}

Several satellite studies of cloud cover and precipitable water vapor (PWV) at the TMT candidate sites were done by Dr. D. André Erasmus and his group (see, for example, Ref. 17). The results of the earlier studies were used for the selection of candidate sites, as described in Section 2 of this report. The main purpose of the later studies was to provide result that are simultaneous with the data taken at the sites. A comparison of satellite and ground data provides a verification of the satellite results and upper limits to the error bars on both. The ground based data can then be put into the context of a study of 28 years of climate parameters from the National Centers for Environmental Prediction (NCEP) reanalysis data set, also done by the Erasmus group, in order to judge whether the conditions encountered during the site testing period were representative for the long-term conditions at the sites. 
Table 2. Dates of first data acquisitions of the different instruments for each candidate site. Note that we only have three sets of SODARs and three IRMAs, which are rotated among the sites. Also note that the $30 \mathrm{~m}$ tower on San Pedro Mártir was set up and operated by the LSST project from December 2005 to May 2006. Testing on Tolar was discontinued in April 2007.

\begin{tabular}{|l|c|c|c|c|c|}
\hline & Tolar & Armazones & Tolonchar & $\begin{array}{c}\text { San Pedro } \\
\text { Mártir }\end{array}$ & $\begin{array}{c}\text { Mauna Kea } \\
13 \mathrm{~N}\end{array}$ \\
\hline \hline Weather station & Apr 03 & Jul 03 & Nov 05 & Oct 04 & Jun 05 \\
DIMM & Oct 03 & Nov 04 & Nov 05 & Oct 04 & Jun 05 \\
MASS & Jan 04 & Nov 04 & Jan 06 & Oct 04 & Jul 05 \\
SODAR & - & Mar 05 & Feb 06 & Mar 06 & Oct 05 \\
All-sky camera & Oct 05 & Oct 05 & Nov 05 & Jul 05 & Jun 06 \\
Sonic anemom. & Feb 06 & Feb 06 & Mar 06 & May 06 & Nov 05 \\
Dust sensor & Feb 06 & Feb 06 & Mar 06 & May 06 & Nov 05 \\
30 m tower & - & Sep 06 & Mar 07 & Dec 05 & - \\
IRMA & - & Jan 07 & Mar 07 & - & Feb 07 \\
\hline
\end{tabular}

\subsection{Instrument Deployment Schedule}

The original goal of the TMT site testing campaign was to take on-site measurements of all major parameters (e.g. weather, seeing) for at least 2 years, and for at least one year for all other parameters. This was achieved or exceeded for most instruments, but was not possible in all cases for practical reasons. Dates of the first deployments of all instruments are shown in Table 2. Note that we do not have five sets of all instruments, so that not all of them have been installed continuously at each site since the dates given in the table. Also, data taken soon after the first deployment dates are not as reliable in some cases as later data and might have to be excluded in the site testing data analysis.

\subsection{Instrument Calibrations and Results Verifications}

Data taken with our instruments are only considered useful for the TMT site selection process if the reliability and uncertainties of the measurements are known. As a result, we have gone through great efforts to understand all instruments and results, including:

- Side-by-side comparisons of identical instruments

- Side-by-side comparisons of different instruments measuring the same parameters

- Sensitivity analyses of the dependence of the results on input parameters

- Independent verification of all in-house analysis software by at least two people

- Independent verification of all results and statistics by at least two people

Details of the calibration efforts have already been published in some cases (see the references in Section 3.1) and exist as TMT internal reports for the other instruments. These will be published shortly. Here, we only present a summary of the uncertainties expected for our instruments (see Table 3). All values given in the table are limits for the statistical properties of the parameters, not for the individual measurements.

A note concerning terminology: We use the term 'absolute error' of a measurement to describe the accuracy of the measurement (defined as the closeness of agreement between the average value obtained from a large series of test results and an accepted reference value). It describes how well our measurements agree with the absolute values of the respective parameters (the "truth"). The term 'relative error' is used to describe the expected relative differences between the measurements taken with identical equipment at different sites, the reproducibility. Both accuracy and reproducibility are difficult to determine in practice. For our results, they are based on the comparison of different equipment at the same sites, whenever possible. When this is not 
Table 3. Summary of the measurement uncertainties as determined from the instrument calibrations. Here, ' $\mathrm{n} / \mathrm{a}$ ' stands for 'not available'. Values given are usually upper limits to the uncertainties of the probability distributions of the respective quantities, although some exceptions apply.

\begin{tabular}{|c|c|c|c|}
\hline & $\begin{array}{c}\text { Relative } \\
\text { Error }\end{array}$ & $\begin{array}{c}\text { Absolute } \\
\text { Error }\end{array}$ & Comments \\
\hline \multicolumn{4}{|l|}{ Weather station sensors } \\
\hline Temperature & $\lesssim 1^{\circ} \mathrm{C}$ & $\lesssim 1^{\circ} \mathrm{C}$ & \\
\hline Temperature on $30 \mathrm{~m}$ tower & $0.1^{\circ} \mathrm{C}$ & $0.1^{\circ} \mathrm{C}$ & \\
\hline Wind speed & $10 \%$ & $10 \%$ & \\
\hline Wind direction & $\lesssim 5^{\circ}$ & $\lesssim 5^{\circ}$ & limited by setup accuracy \\
\hline Humidity & $10 \%$ & $10 \%$ & non-linear in mid range (around $30 \%$ ) \\
\hline Pressure & $1 \mathrm{hPa}$ & $1 \mathrm{hPa}$ & vendor quoted accuracy \\
\hline Solar irradiance & $\mathrm{n} / \mathrm{a}$ & $\mathrm{n} / \mathrm{a}$ & not needed \\
\hline Precipitation & $\mathrm{n} / \mathrm{a}$ & $\mathrm{n} / \mathrm{a}$ & used for equipment safety only \\
\hline Heat flux & $5 \%$ & $5 \%$ & vendor quoted accuracy \\
\hline Net radiation & $3 \%$ & $3 \%$ & vendor quoted accuracy \\
\hline \multicolumn{4}{|l|}{ DIMM } \\
\hline Seeing & 0. & similar & \\
\hline \multicolumn{4}{|l|}{ MASS } \\
\hline Free-atmosphere seeing & 0.05 & similar & \\
\hline Individual layers $\left(C_{n}^{2} \mathrm{~d} h\right)$ & $10^{-14} \mathrm{~m}^{1 / 3}$ & similar & \\
\hline Isoplanatic angle & $0^{\prime \prime} 02$ & $<0^{\prime \prime} 2$ & \\
\hline Coherence time & $20 \%$ & $20 \%$ & \\
\hline \multicolumn{4}{|l|}{ SODAR } \\
\hline Wind profiles & $20 \%$ & $\sim 1 \mathrm{~m} / \mathrm{s}$ & offsets exist between SFAS and XFAS \\
\hline GL seeing & $10 \%$ & similar & \\
\hline Individual layers & $\sim 20 \%$ & similar & \\
\hline \multicolumn{4}{|l|}{ Sonic anemometer } \\
\hline Wind speed & $<5 \%$ & $<5 \%$ & \\
\hline Wind direction & $\lesssim 5^{\circ}$ & $\lesssim 5^{\circ}$ & limited by setup accuracy \\
\hline Sonic temperature & $<3^{\circ} \mathrm{C}$ & $<3^{\circ} \mathrm{C}$ & offsets exist \\
\hline \multicolumn{4}{|l|}{ Dust sensor } \\
\hline Particle count & $10 \%$ & $\mathrm{n} / \mathrm{a}$ & \\
\hline All-sky camera & & & \\
\hline Cloud cover & $1-4 \%$ & $1-4 \%$ & site dependent \\
\hline IRMA & & & \\
\hline Precipitable water vapor & $\sim 0.25 \mathrm{~mm}$ & $\mathrm{n} / \mathrm{a}$ & additive offsets exist; site dependent \\
\hline Satellite data & & & \\
\hline Cloud cover & $2-6 \%$ & $2-6 \%$ & site dependent \\
\hline Precipitable water vapor & $20 \%$ & $20 \%$ & \\
\hline
\end{tabular}

possible, we estimate them based on investigations of the repeatability of the measurements (the expected relative differences between the measurements taken with identical equipment at the same site) and on sensitivity and bias analyses of the instruments.

\section{TMT SITE TESTING AVAILABLE RESULTS}

The TMT site testing results are currently written up in a series of TMT internal reports and will be published shortly. The kind of results available in the TMT reports include:

Statistics covering the entire on-site testing period:

DIMM, MASS and ground layer (GL) seeing and isoplanatic angle statistics

MASS turbulence profile statistics 
SODAR seeing, wind and turbulence profile statistics

Night- and daytime meteorological parameter statistics at the 2 and $7 \mathrm{~m}$ levels

Night- and daytime wind roses for the 2 and $7 \mathrm{~m}$ levels

Daily temperature / temperature gradient statistics for the 2 and $7 \mathrm{~m}$ levels

Daily wind speed / wind speed gradient statistics for the 2 and $7 \mathrm{~m}$ levels

Daily minimum, maximum and sunset temperature and wind speed statistics

Correlations between DIMM, MASS, GL seeing and wind speeds at 2 and $7 \mathrm{~m}$ levels

Dust sensor particle counts

Ground and energy property statistics (soil temperature, energy fluxes)

Temperature and wind speed profiles along the $30 \mathrm{~m}$ towers

Temperature and wind speed gradient profiles along the $30 \mathrm{~m}$ towers

Statistics of meteorological parameters for each level of the $30 \mathrm{~m}$ towers

Daily temperature / temperature gradient statistics for each level of the $30 \mathrm{~m}$ towers

Daily wind speed / wind speed gradient statistics for each level of the $30 \mathrm{~m}$ towers

Monthly statistics:

DIMM, MASS and ground layer (GL) seeing and isoplanatic angle

Meteorological parameter statistics at the $2 \mathrm{~m}$ and $7 \mathrm{~m}$ levels

Meteorological parameter statistics for each level of the $30 \mathrm{~m}$ towers

The results also include comparative plots of the candidate sites for some of the main statistical properties, such as:

Monthly DIMM and MASS seeing, isoplanatic angle, temperature and wind speed

Cumulative DIMM and MASS seeing, isoplanatic angle, temperature and wind speed

Median MASS turbulence profiles

The TMT site testing data are available in a database and can be downloaded using a web interface on the TMT site testing web site. This site also lists known issues with the data sets, such as periods when sensors malfunctioned and data need to be excluded, or whether certain data require post processing. The web site is currently only accessible with a password. It will be made publicly available once analysis is complete.

\section{ACKNOWLEDGMENTS}

The TMT site testing group would like to express a particular appreciation for the contributions of the late Juan Araya, André Erasmus and Hugo Schwarz, and our sadness over the loss of their company and friendship.

The TMT site testing work could not have happened without the contributions of many other people at various institutions. A special thanks to everybody who has supported, and is still supporting, the TMT site testing program, in particular the people at the Cerro Tololo Inter-American Observatory (CTIO), the National Optical Astronomy Observatory (NOAO) and the AURA New Initiatives Office (NIO), the Universidad Católica del Norte in Antofagasta, the Observatorio Astronómico Nacional de San Pedro Mártir, Gemini Observatory, Palomar Observatory, the Submillimeter Array (SMA), the University of Hawaii Institute for Astronomy (IfA), the University of Lethbridge, the University of Moscow, the South African Astronomical Observatory (SAAO), and the entire TMT project including its partner institutions and external reviewers.

The authors gratefully acknowledge the support of the TMT partner institutions. They are the Association of Canadian Universities for Research in Astronomy (ACURA), the California Institute of Technology and the University of California. This work was supported as well by the Gordon and Betty Moore Foundation, the Canada Foundation for Innovation, the Ontario Ministry of Research and Innovation, the National Research Council of Canada, the Natural Sciences and Engineering Research Council of Canada, the British Columbia Knowledge Development Fund, the Association of Universities for Research in Astronomy (AURA) and the U.S. National Science Foundation. 


\section{REFERENCES}

[1] Schöck, M., Els, S., Riddle, R., Skidmore, W., and Travouillon, T., "Status of the TMT Site Evaluation Process," in [Revista Mexicana de Astronomia y Astrofisica Conference Series], 31, 10-17 (Oct. 2007).

[2] Zhou, J. and Lau, K.-M., "Does a Monsoon Climate Exist over South America?.," Journal of Climate 11, 1020-1040 (May 1998).

[3] Sarazin, M. and Roddier, F., "The ESO differential image motion monitor," Astron. Astrophys. 270, 294-300 (1990).

[4] Travouillon, T., Els, S., Riddle, R., Schöck, M., Skidmore, A., Bustos, E., Seguel, J., Walker, D., Vasquez, J., Blum, R., Gillett, P., and Gregory, B., "Temporal variability of the seeing of TMT sites," in [Ground-based and Airborne Telescopes], Stepp, L. M. and Gilmozzi, R., eds., Proc. SPIE 7012 (2008).

[5] Wang, L., Schöck, M., Chanan, G., Skidmore, W., Blum, R., Bustos, E., Els, S., Riddle, R., Seguel, J., Travouillon, T., Vasquez, J., Walker, D., and Gillett, P., "High-accuracy differential image motion monitor measurements for the Thirty Meter Telescope site testing program," Appl. Opt. 46, 6460-6468 (Sept. 2007).

[6] Kornilov, V., Tokovinin, A. A., Vozyakova, O., Zaitsev, A., Shatsky, N., Potanin, S. F., and Sarazin, M. S., "MASS: a monitor of the vertical turbulence distribution," in [Adaptive Optical System Technologies II], Wizinowich, P. L. and Bonaccini, D., eds., Proc. SPIE 4839, 837-845 (Feb. 2003).

[7] Els, S., Schöck, M., Seguel, J., Tokovinin, A., Kornilov, V., Riddle, R., Skidmore, W., Travouillion, T., Vogiatzis, K., Blum, R., Bustos, E., Gregory, B., Vasquez, J., Walker, D., and Gillett, P., "Study on the precision of the MASS turbulence profiler employed in the site testing campaign for the Thirty Meter Telescope," Appl. Opt. (2008). Accepted for publication.

[8] Els, S., Schöck, M., Seguel, J., Skidmore, W., Walker, D., Tokovinin, A., Kornilov, V., Riddle, R., Travouillon, T., Bustos, E., Vasquez, J., Blum, R., Gregory, B., and Gillett, P., "The Multi Aperture Scintillation Sensor (MASS) used in the site selection of the Thirty Meter Telescope (TMT)," in [Ground-based and Airborne Telescopes], Stepp, L. M. and Gilmozzi, R., eds., Proc. SPIE 7012 (2008).

[9] Skidmore, W., Schöck, M., Magnier, E., Walker, D., Feldman, D., Riddle, R., Els, S., Bustos, E., Seguel, J., and Gillett, P., "Using All Sky Cameras to determine cloud statistics for the Thirty Meter Telescope candidate sites," in [Ground-based and Airborne Telescopes], Stepp, L. M. and Gilmozzi, R., eds., Proc. SPIE 7012 (2008).

[10] Travouillon, T., "SODAR calibration for turbulence profiling in TMT site testing," in [Ground-based and Airborne Telescopes], Stepp, L. M., ed., Proc. SPIE 6267 (2006).

[11] Skidmore, W., Travouillon, T., and Riddle, R., "Evaluation of sonic anemometers as highly sensitive optical turbulence measuring devices for the Thirty Meter Telescope site testing campaign," in [Ground-based and Airborne Telescopes], Stepp, L. M., ed., Proc. SPIE 6267 (2006).

[12] Walker, D. E., Schwarz, H. E., and Bustos, E., "Monitoring the night sky with the Cerro Tololo All-Sky camera for the TMT and LSST projects," in [Ground-based and Airborne Telescopes], Stepp, L. M., ed., Proc. SPIE 6267 (2006).

[13] Riddle, R. L., Walker, D., Schöck, M., Els, S. G., Skidmore, W., Travouillon, T., Bustos, E., Seguel, J., Vasquez, J., Blum, R. D., Gillett, P., and Gregory, B., "An analysis of light pollution at the Thirty Meter Telescope candidate sites," in [Ground-based and Airborne Telescopes], Stepp, L. M. and Gilmozzi, R., eds., Proc. SPIE $\mathbf{7 0 1 2}$ (2008).

[14] Phillips, R. R. and Naylor, D. A., "Initial operations of a water vapour monitor (IRMA) at Gemini South, Las Campanas Observatories, and in the TMT site testing role," in [Ground-based and Airborne Instrumentation for Astronomy], McLean, I. S. and Iye, M., eds., Proc. SPIE 6269 (July 2006).

[15] Riddle, R. L., Schöck, M., and Skidmore, W., "The Thirty Meter Telescope site testing robotic computer system," in [Ground-based and Airborne Telescopes], Stepp, L. M., ed., Proc. SPIE 6267 (2006).

[16] Els, S. G. and Vogiatzis, K., "TMT studies on the influence of short term changes of local thermodynamic conditions on the seeing: CFD vs. observations," in [Ground-based and Airborne Telescopes], Stepp, L. M., ed., Proc. SPIE 6267 (2006).

[17] Schoeck, M., Erasmus, D. A., Djorgovski, S. G., Chanan, G. A., and Nelson, J. E., "CELT site testing program," in [Future Giant Telescopes], Angel, J. R. P. and Gilmozzi, R., eds., Proc. SPIE 4840, 541-552 (Jan. 2003). 